\title{
THE DYE-BINDING CAPACITY OF HUMAN PLASMA DETERMINED FLUORIMETRICALLY AND ITS RELATION TO THE DETERMINATION OF PLASMA ALBUMIN
}

\author{
BY \\ V. H. REES, J. E. FILDES, AND D. J. R. LAURENCE \\ From the Department of Chemical Pathology, Postgraduate Medical School of London
}

(RECEIVED FOR PUBLICATION MARCH, 1954)

The binding of acidic dyes and other negatively charged ions is a well-known property of the proteins of blood plasma and is a specific property of the albumin fractions, the globulin fractions being almost inactive in this respect. This is easily observed when an acidic dye such as bromophenol blue is added to plasma and the plasma then subjected to electrophoresis on filter paper. The blue dye travels solely with the plasma albumin, leaving the globulin fractions unstained. A similar result is observed with the naturally occurring bile pigments in jaundiced plasma. Much further evidence is available for this specific property of plasma albumin and has been reviewed by Goldstein (1949), by Klotz (1949), and by Edsall (1947).

Smith and Smith (1938) showed that for a number of plasmas from pathological as well as normal states the retention of phenol red by an ultrafiltration membrane was closely related to the albumin content of the plasma. Rosenfeld and Surgenor (1952) have proposed a method of estimation of human plasma albumin in whole plasma by using the interaction with haematin, the extent of the interaction being measured spectrophotometrically.

In the present paper, the substance 1-anilinonaphthalene-8-sulphonic acid is used to estimate the dye-binding capacity of human plasma from a number of pathological conditions. The substance is non-fluorescent in aqueous solution, but brightly fluorescent when absorbed by plasma albumin and is one of a class of compounds with this unusual property described elsewhere (Weber and Laurence, 1954). The method to be described depends on the use of a limited amount of plasma, so that the fluorescent substance is always present in excess of the dye-binding capacity. The amount of dye bound is then a measure of the dye-binding capacity of the plasma and it is evaluated from the fluorescent intensity as only the bound dye is fluorescent. By using standard solutions of a purified albumin to relate albumin concentration with dye-binding capacity, the fluorescent intensities may be converted to equivalent albumin concentrations. Comparisons between these estimates and results of independent determinations by standard techniques are given. As no generally accepted absolute method of albumin determination in plasma is available, the best criterion of the validity is statistical agreement between any two independent methods. This criterion is used to assess the fluorimetric methods and also the standard methods of albumin determination.

\section{Fluorimetric Methods}

Reagents.-The following reagents were used in the fluorimetry:-

Fluorescent Standard Solution.-1-Naphthylamine6(7)-sulphonic acid (B.D.H.), $40 \mathrm{mg}$., was dissolved in $100 \mathrm{ml}$. of $0.1 \mathrm{M}$-borate buffer $(p \mathrm{H} \mathrm{9.2)} \mathrm{and} \mathrm{diluted}$ to 1 litre with water.

Stock Dye Solution.-1-Anilinonaphthalene-8-sulphonic acid was prepared by the method of Hodgson and Marsden (1939) and $4 \mathrm{mg}$. was dissolved in an equivalent amount of $0.1 \mathrm{~N}-\mathrm{NaOH}$ and diluted to $500 \mathrm{ml}$. with water.

The 1-anilinonaphthalene-8-sulphonic acid was prepared by heating together for 15 hours at $150^{\circ} \mathrm{C}$. a mixture of 1-naphthylamine-8-sulphonic acid (15 g.), aniline ( $23 \mathrm{~g}$.), and aniline hydrochloride $(9 \mathrm{~g}$.) in a flask fitted with mechanical stirring and a reflux condenser. The product was extracted with sodium hydroxide and the extract was acidified with acetic acid. Impurities of a deep brown colour were removed by treating the solution with activated charcoal and the purified sulphonic acid was then crystallized by the addition of concentrated hydrochloric acid. 
Human Plasma Albumin Solution.-The crystalline protein (Massachusetts Biologic Laboratories, obtained from the Smith, Kline and French Laboratories, Philadelphia, as a gift) was dissolved in isotonic saline to give a $4 \%(w / v)$ solution.

Bovine Plasma Albumin Solution.-The crystalline protein (Armour and Company, Ltd.) was dissolved in isotonic saline to give a $4 \%(w / v)$ solution.

Phosphate Buffer.-Six volumes of $\mathrm{M} / 15$ disodium hydrogen phosphate were mixed with 4 volumes of $\mathrm{M} / 15$ potassium dihydrogen phosphate.

Isotonic Saline.-Sodium chloride solution, 0.9\% $(\mathrm{w} / \mathrm{v})$, in water.

Solution A.-For the estimation of dye-binding capacity, $250 \mathrm{ml}$. of the stock dye solution were mixed with $50 \mathrm{ml}$. of the phosphate buffer and $50 \mathrm{ml}$. of isotonic saline. This mixture is called "Solution A."

The Fluorimeter.-In early work the fluorescent intensity was measured visually using a modified Pulfrich photometer. The procedure to be described was adapted for use with a photoelectric fluorimeter in order to eliminate subjective errors.

The photoelectric measurement of fluorescent intensity was made using a photomultiplier type R.C.A. 931-A operated from a number of $120 \mathrm{v}$. high tension dry batteries. A Pye "scalamp" galvanometer with a linear scale was used as the measuring instrument. A G.E.C. 80 watt mercury lamp, type MB/V, with a clear glass envelope provided the light for excitation of the fluorescence which was passed through a Chance light filter OX 7 before entering the fluorimeter. The fluorescent solutions were placed for measurement in parallel-sided cells $(4 \mathrm{~cm} . \times 2 \mathrm{~cm}$. $\times 1 \mathrm{~cm}$. internal dimensions) illuminated on a larger face. The fluorescent intensity was measured in a direction at right angles to the direction of excitation by the photomultiplier, provided with a Chance OY 18 light filter.

Procedure.-Into $7 \mathrm{ml}$. of solution A was pipetted $0.05 \mathrm{ml}$. of the plasma to be tested and the solution was well mixed. Into another $7 \mathrm{ml}$. of solution A was pipetted $0.05 \mathrm{ml}$. of either the human or the bovine plasma albumin solutions.

The voltage across the photomultiplier was adjusted until the fluorescent intensity of the fluorescent standard solution corresponded to 67 galvanometer scale units (full scale deflection $=140$ units). This adjustment was subsequently checked between each pair of fluorimetric readings.

The fluorescent intensity of the solution $A$ with added plasma albumin solution was measured and confirmed to be either 70 (human albumin) or 90 (bovine albumin).

The fluorescent intensity of the solution $A$ with added test plasma was measured and the corresponding albumin concentration obtained from a standard curve. This standard curve had previously been constructed by adding varying volumes of the human plasma albumin solution to $7 \mathrm{ml}$. of solution A.
The albumin concentration so obtained was compared with the albumin concentration estimated by independent methods.

\section{Methods of Albumin Estimation}

The estimates of plasma albumin concentration used in this work were mainly obtained during routine analysis of hospital samples. The methods used were three routine methods available at various times during the past two years.

These methods were as follows: (a) The salt fractionation procedure of Campbell and Hanna as described by King (1951) using sodium sulphite; (b) electrophoresis on filter paper as described by Knedel (1951) using the electrophoresis chambers and dye (amidoschwarz 10 B) supplied by Bender and Hobein (Munich) and a commercial densitometer. A washing solution consisting of $10 \%(\mathrm{v} / \mathrm{v})$ glacial acetic acid in methanol (2 parts) diluted with water (1 part) and $0.01 \mathrm{~N}$ with respect to hydrochloric acid (Herbert, D., unpublished observations) was used to remove the background colour from the dyed filter paper strips. (c) Electrophoresis on filter paper in which the recording densitometer (Laurence, 1954) was used for evaluating the dyed strips. Procedure otherwise as in $(b)$.

In methods $(b)$ and $(c)$ the total protein concentration is required and was estimated by the Van Slyke copper sulphate method as described by King (1951).

(d) In addition to these three routine methods, a method of paper electrophoresis was used for which the evaluation of the albumin concentration is independent of assumptions concerning the relative densities of the dyed protein fractions and does not require a knowledge of the total protein concentration.

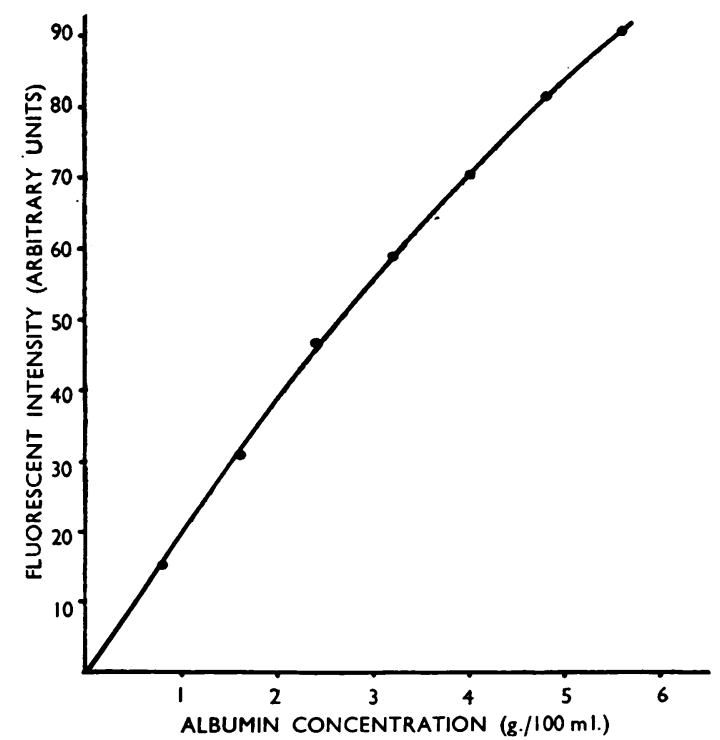

FIG. 1. Standard curve relating the fluorescent intensity of the dyeprotein mixture with the albumin concentration. 
A $4 \%$ solution of the human plasma albumin was applied to the filter paper strip as a narrow band about 2 inches in advance of the test plasma, the volumes of both the albumin solution and the test plasma being exactly $10 \mu \mathrm{l}$. After electrophoresis the

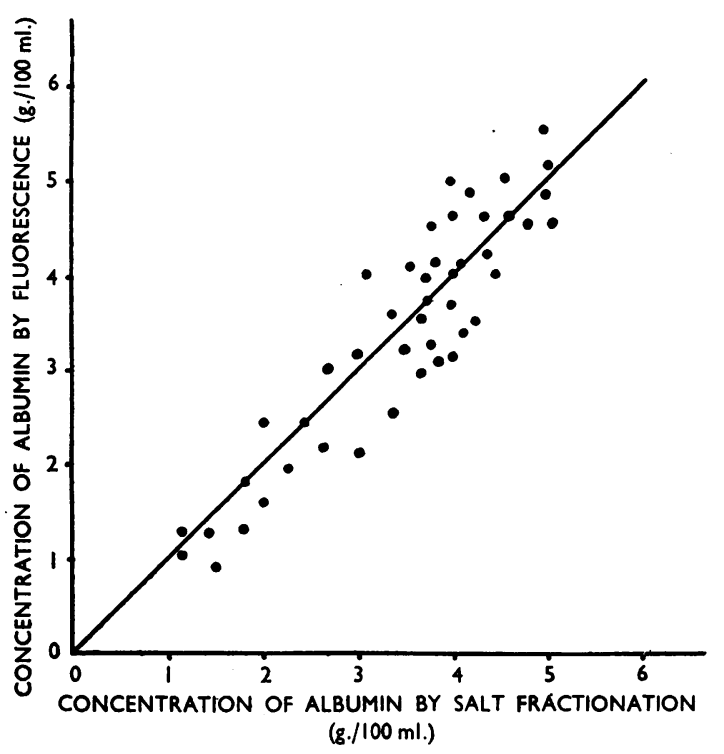

Fig. $2 a$

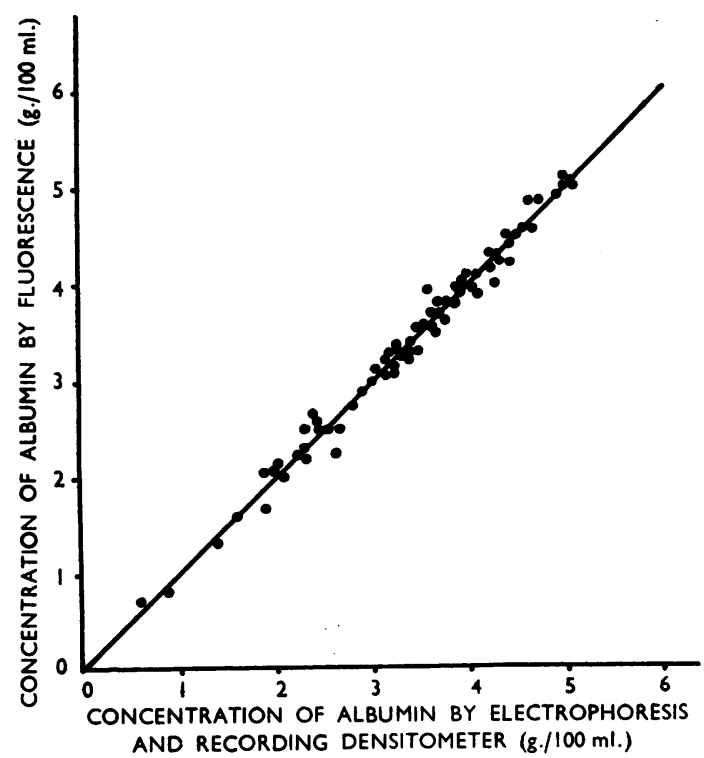

Fio. $2 c$ dried filter paper strip was developed with bromphenol blue as described by Kunkel and Tiselius (1951), and the dyed bands corresponding to the albumin of the standard solution and of the test plasma were cut out, eluted, and compared colorimetrically.

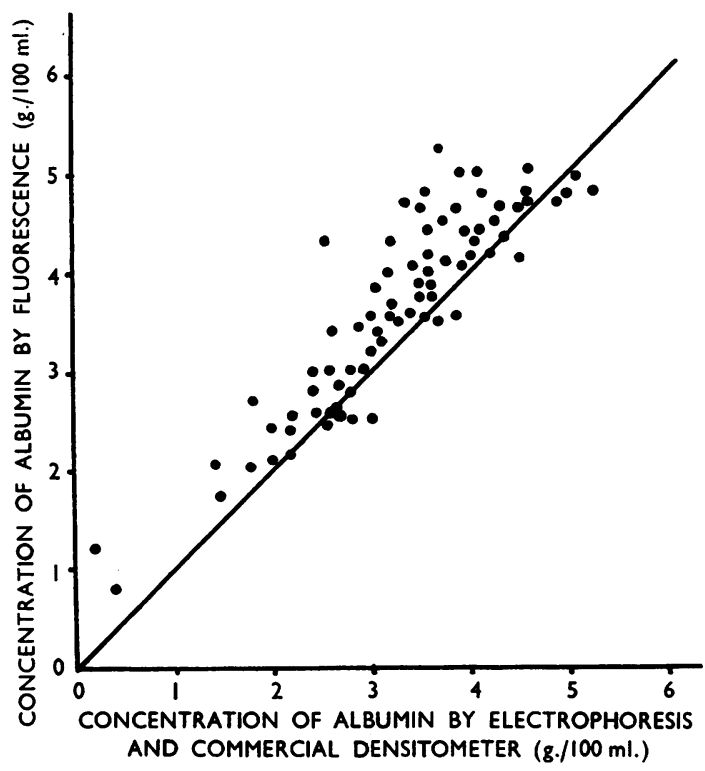

Fig. $2 b$

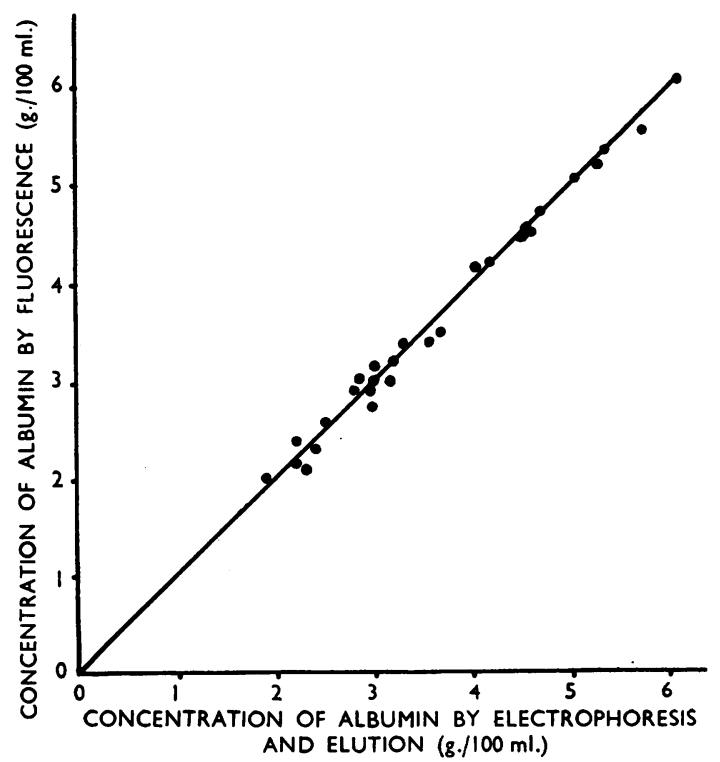

FIG. 2d

FIG. 2.-Comparisons of the albumin concentration determined fluorimetrically with the albumin concentrations determined by: (a) salt fractionation, (b-d) electrophoresis, $(b)$ a commercial densitometer, $(c)$ the recording densitometer, $(d)$ the elution method. Curves $a-d$ correspond to methods $a-d$ described in the text. 


\section{Results}

Fig. 1 shows the standard curve by which the apparent albumin concentration may be estimated from the values of fluorescent intensity.

Figs. $2 a-d$ give the results obtained by comparing the apparent albumin concentrations obtained fluorimetrically with the values obtained by the methods $(a-d)$ outlined above. The values obtained for samples of plasma from cases of obstructive and hepatic jaundice have been shown separately in Fig. 3 since these require special consideration.

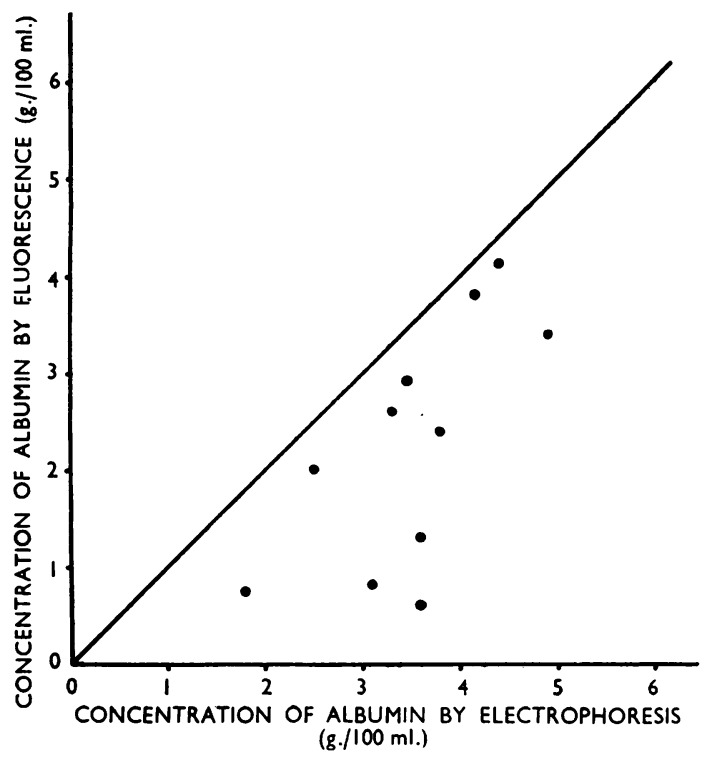

FIG. 3.-Comparisons of the albumin concentration determined fluorimetrically with the albumin concentration determined electrophoretically in cases of obstructive and hepatic jaundice.

Table I summarizes the distribution of differences irrespective of sign between the fluorimetric method and the various independent methods of estimating the albumin concentration. It will be seen that methods $(c)$ and $(d)$ give by far the most satisfactory agreement between the methods. The errors observed are no more than would be expected from apparent limitations of the methods and no systematic error is discernible in Figs. $2 c$ and $2 d$.

\section{Discussion}

As the methods described here for electrophoresis on filter paper utilize a form of binding acidic dyes, the use of these methods as an independent check on the fluorimetric method requires justification. The dye binding in neutral aqueous solution as measured by the fluorimetric method is a specific property of the native albumin
TABLE I

DISTRIBUTION OF DIFFERENCES BETWEEN ALBUMIN CONCENTRATION DETERMINED FLUORIMETRICALLY AND BY OTHER METHODS*

\begin{tabular}{|c|c|c|c|c|c|c|c|}
\hline \multirow[t]{2}{*}{ Method } & \multicolumn{6}{|c|}{$\begin{array}{l}\text { Differences between Esti- } \\
\text { mated Concentration } \\
(\mathrm{g} . / 100 \mathrm{ml} \text {. to nearest } 0.1 \mathrm{~g} .)\end{array}$} & \multirow{2}{*}{$\begin{array}{c}\text { Average } \\
\text { Difference } \\
\text { (g./100 ml.) }\end{array}$} \\
\hline & 0 & 0.1 & $0 \cdot 2$ & $0 \cdot 3$ & 0.4 & $>0.4$ & \\
\hline $\begin{array}{l}\text { (a) Salt fractionation . } \\
\text { (b) Electrophoresis and } \\
\text { commercial densito- } \\
\text { meter... . } \\
\text { (c) Electrophoresis and } \\
\text { recording densitometer } \\
\text { (d) Electrophoresis and } \\
\text { elution } \quad .\end{array}$ & $\begin{array}{l}29 \\
10\end{array}$ & $\begin{array}{l}33 \\
12\end{array}$ & $\begin{array}{l}21 \\
22\end{array}$ & $\begin{array}{r}16 \\
2\end{array}$ & $\begin{array}{r}15 \\
3\end{array}$ & 30 & $\begin{array}{l}0.1 \\
0.1\end{array}$ \\
\hline
\end{tabular}

*ach entry gives the number of cases with a given difference.

fraction. It is destroyed by heating the solution at $100^{\circ}$ for 15 minutes and is related to a maximum capacity of about 3 molecules of dye bound for each molecule of protein. In contrast, the dye binding on proteins in paper electrophoresis is a general property of all coagulated proteins in an acidic dye bath. Heating at $105^{\circ}$ for 15 minutes is a standard procedure to promote dye binding, and more than 20 molecules of dye are bound for each molecule of protein. It is likely, therefore, that the two methods are independent. This conclusion is strengthened by the good agreement that has been obtained by many workers between the results of electrophoresis on filter paper and by the classical moving boundary method of Tiselius, the latter method depending on refractive index measurement to obtain an estimate of protein concentration.

Good agreement has been found between the plasma albumin concentration and the dye-binding capacity of the plasma, when this is expressed in terms of the dye-binding capacity of crystalline human plasma albumin (Figs. $2 c$ and $2 d$ ). Since the dye-binding capacity is readily measured, it has formed a valuable check on the methods of protein estimation which have been used routinely.

The dye-binding capacity was consistently low in cases of obstructive and hepatic jaundice (Fig. 3), but the possibility of an artifact due to absorption of the fluorescent light by the bile pigments has not yet been ruled out. No other diseases associated with the characteristically abnormal dyebinding capacity of the plasma have been recognized, although the cases illustrated in Figs. $2 a-d$ include a random and miscellaneous collection of disease including nephrosis and nephritis.

By comparison of the various Figs. $2 a-d$ some typical errors in some methods of albumin determination can be recognized. The wide scatter of the results of salt fractionations (Fig. $2 a$ ) and the 
high values for albumin, especially at low concentrations, have been recognized elsewhere (Pillemer and Hutchinson, 1945). The commercial densitometer gave results leading to an underestimation (Fig. $2 b$ ) of the albumin concentration, possibly owing to stray light leaking at the edges of the protein bands. In contrast, the recording densitometer (Fig. 2c) and the elution technique (Fig. $2 d$ ) both lead to satisfactory agreement with the fluorimetric determinations. In a series of normal plasmas (Kind, Rees, and Schmidt, unpublished data) a similar good agreement between the fluorimetric and the densitometric techniques was obtained.

The fluorimetric technique is especially simple to use since the fluorescent intensity of the 1anilinonaphthalene-8-sulphonic acid is negligible in the absence of albumin and almost linear with albumin concentration. The results of this work confirm that purification and crystallization do not alter the dye-binding capacity of human serum albumin.

\section{Summary}

The dye-binding capacity of plasma has been measured in a random selection of pathological cases. There is a close, almost linear, relationship between the dye-binding capacity and the concentration of the plasma albumin.

Low values of dye-binding capacity are obtained in obstructive and hepatic jaundice.

The application of this method to check routine methods of protein estimation is illustrated.

The authors would like to thank Professor E. J. King and Dr. G. Weber for helpful encouragement.

\section{REFERENCES}

Edsall, J. T. (1947). Advanc. Protein Chem., 3, 463.

Goldstein, A. (1949). Pharmacol. Rev., 1, 102.

Hodgson, H. H., and Marsden, E. (1939). J. Soc. chem. Ind., Lond., (Trans.) $58,154$.

King, E. J. (1951). Micro-analysis in Medical Biochemistry, 2nd ed., p. 50 . Churchill, London.

Klot. I (1949). Cold SprHarb. Symp. quant. Biol., 14, 97.

Knedel, M. (1951). Med. Mschr., 5, 707.

Kunkel, H. G., and Tiselius, A. (1951). J. gen. Physiol., 35, 89.

Laurence, D. J. R. (1954). J. sci. Instrum., 31, 137.

Pillemer, L., and Hutchinson, M. C. (1945). J. biol. Chem., 158, 299.

Rosenfeld, M., and Surgenor, D. M. (1952). Ibid., 199, 911 .

Smith, W. W., and Smith, H.W. (1938). Ibid., 124, 107.

Weber, G., and Laurence, D. J. R. (1954). Biochem. J., 56, xxxi. 